Diabetologia 9, 299-302 (1973)

(c) by Springer-Verlag 1973

\title{
Time Course Studies of Glucose-Induced Changes in Glucose-6-Phosphate and Fructose-1,6-Diphosphate Content of Mouse and Rat Pancreatic Islets
}

\author{
S.J.H. Ashcroft, K. Capito and C.J. Hedeskov \\ Department of Biochemistry A, University of Copenhagen, Denmark \\ Received: February 9, 1973, accepted May 4, 1973
}

Summary. The concentrations of glucose 6-phosphate (G6P) and fructose 1-6-diphosphate plus triose-phosphates (FDP - TPs) were moasured in isolated islets of Langerhans from mice and rats after a sudden increase in extracellular glucose concentration from 0.5 to $3.4 \mathrm{mg} / \mathrm{ml}$. In mouse islets, the contents of G6P and (FDP + TPS) were both raised after a two minute incubation at the high glucose concentration and remained elevated for at least $30 \mathrm{~min}$. In rat islets, the G6P but not the (FDP + TPs) content was increased after a 5 min exposure to high glucose. After a 30 min incubation, both $G 6 \mathrm{P}$ and (FDP + TPs) contents were higher than at low glucose concentration. The (G6P)/(FDP + TPs) ratio was some tenfold higher in mouse islets than in rat islets. Increasing extracellular glucose concentration was associated with an increase in the $(G 6 P) /(F D P+T P s)$ ratio. The results are consistent with the increased glycolytic rate in response to a raised extracellular glucose concentration arising primarily from an increase in the rate of phosphorylation of glucose, and with the hypothesis that the insulin secretory response to glucose may be mediated by a metabolite of the sugar.

Key words: Islet metabolism, insulin release, hexose phosphate, luciferase assay of pyridine nucleotides.

\section{Introduetion}

To substantiate the hypothesis that metabolites of glucose or conditions associated with glucose metabolism, rather than glucose itself, trigger insulin release from the islets of Langerhans [1,2], it would be necessary to show that changes in concentrations of metabolites or cofactors occur at least as fast as insulin secretion switches on after a glucose pulse.

In in vivo experiments with islets from obese hyperglycemic mice a $400 \%$ rise in $\mathrm{G}^{6} \mathrm{P}^{\mathbf{1}}$ concentration within 90 sec has been demonstrated [3]. However, later Matschinsky et al. [4] again using an in vivo approach - found no changes in the concentrations of $\mathrm{G} 6 \mathrm{P}, 6 \mathrm{PG}^{1}, \mathrm{ATP}$ or phosphocreatine in rat islets within $1-5$ min after a glucoso pulse.

We felt that this species difference in metabolic response possibly could be explained by differences in anaesthesia, in the degree of hypoxia and stress and/or other experimental conditions difficult to control in vivo and have therefore in in vitro experiments measured the concentrations of $\mathrm{G} 6 \mathrm{P}$ and $(\mathrm{FDP}+\mathrm{TPs})^{1}$ in isolated islets of Langerhans from both mice and rats after a sudden rise in extracellular glucose concentration from 0.5 to $3.4 \mathrm{mg} / \mathrm{ml}$.

Significant and fast changes in the concentration of metabolites were demonstrated in both rat- and mouse islets although most pronounced in mouse islets.

1 Abbreviations used: G6P: glucose-6-phosphate, FDP + TPs: fructose-1,6-diphosphate plus triose phosphates, 6PG: 6-phosphogluconate.

\section{Materials and Methods}

Purified luciferase from Achromobacter fischerii and FMN were from Sigma Chemical Co. Myristic aldehyde was from Aldrich Chemical Co. Other enzymes and coenzymes used were from Boehringer. Human albumin was from Behringwerke $\mathrm{AG}$. All other reagents were of analytical grade.

All glassware used was cleaned in $1.5 \mathrm{~N}$ nitric acid and washed in double distilled water.

\section{Preparation of Islets}

Islets were isolated by a collagenase method [5] from the pancreas of male Wistar rats weighing $150-175 \mathrm{~g}$ or of male T. O. mice weighing $22-26 \mathrm{~g}$. All animals were starved overnight.

\section{Incubation of Islets}

Batches of 7 -- 10 islets (for glucose-6-phosphate assay) or 20-40 islets (for fructose-1,6-diphosphate assay) were preincubated for $30 \mathrm{~min}$ at $37^{\circ}$ in stoppered glasstubes with $21, u 1$ gassed $\left(\mathrm{O}_{2}: \mathrm{CO}_{2}\right.$ 95:5) Krebs bicarbonate buffer [6] containing $0.5 \mathrm{mg}$ glucose $/ \mathrm{ml}$ and $1 \mathrm{mg}$ human albumin $/ \mathrm{ml}$.

After preincubation, the glucose concentration of the medium was raised by injecting $7 \mu \mathrm{l} \mathrm{Krebs} \mathrm{bicarbonate}$ buffer containing $12 \mathrm{mg}$ glucose $/ \mathrm{ml}$ and $1 \mathrm{mg}$ human albumin $/ \mathrm{ml}$. After the time indicated in the tables the metabolism was stopped by injecting $28 \mu l 0.1 \mathrm{~N}$ HCl (for G6P assay) or $1 \mathrm{~N}$ HCl (for FDP assay). The low glucose controls were prepared by adding the HCl immediately after the preincubation and then later the $7 \mu 1$ Krebs buffer with high glucose content. Blank values were obtained by incubating medium without islets.

Before assaying for $G 6 \mathrm{P}$ or $\mathrm{FDP}$ all tubes were sonicated for 20 sec at position 1 on a Branson Sonifier B-12.

FDP and G6P standards were made up in a Krobs bicarbonate medium-HCl mixture similar in composition to the acidified incubation medium in order to account for 
any interference by the medium reagents in the metabolite assays.

\section{Glucose.6-Phosphate Assay}

$40 \mu \mathrm{I}$ of the sonicate or standard G6P solutions were analysed for G6P by adding $27 \mu l$ of $0.2 \mathrm{M}$ trisbuffer $\mathrm{pH}$ $8.0,1.5 \mu l 1 \mathrm{mM} \mathrm{NADP}^{+}$and $1.5 \mu \mathrm{l}$ glucose-6-phosphate dehydrogenase $(0.35 \mathrm{U} / \mathrm{ml})$. After incubation for $60 \mathrm{~min}$ at room temperature the content of NADPH was measured in triplicate by the luciferase assay described below.

\section{Fructose-,1-6Diphosphate Assay}

$40 \mu \mathrm{l}$ of the sonicate or standard FDP solutions were analysed for FDP and triose phosphates by adding $27 \mu 1$ $0.4 \mathrm{M}$ trisbuffer containing $0.5 \mathrm{~N} \mathrm{KOH}, 1 \mathrm{mM}$ mercapto- saturated solution of myristic aldehyde in ethanol and $20 \mu l$ of the sample to be determined were added to the tubes. The tubes were allowed to stand at room temperature in the dark for $10-15 \mathrm{~min}$ and the assay was started by adding $40 \mu \mathrm{l}$ of a luciferase-solution containing $1 \mathrm{mg}$ luciferase $/ \mathrm{ml}$ phosphate buffer $\mathrm{pH} 7.0$ to the tube. The tube was quickly removed from the dark, mixed on a Vortex-Genie and transferred to a conventional glass scintillation vial placed in the liquid scintillation spectrometer and counted for $0.1 \mathrm{~min}$.

The time passing $(15 \mathrm{sec})$ from the adding of the luciferase until the start of the counting was accurately standardized by always adding the luciferase when the printing out of the results of the preceeding tube started. A Packard TriCarb scintillation spectrometer, model 2002

Table 1. Glucose-6-phosphate and fructose-1, 6-diphosphate in islets of Langerhans

Mouse Islets

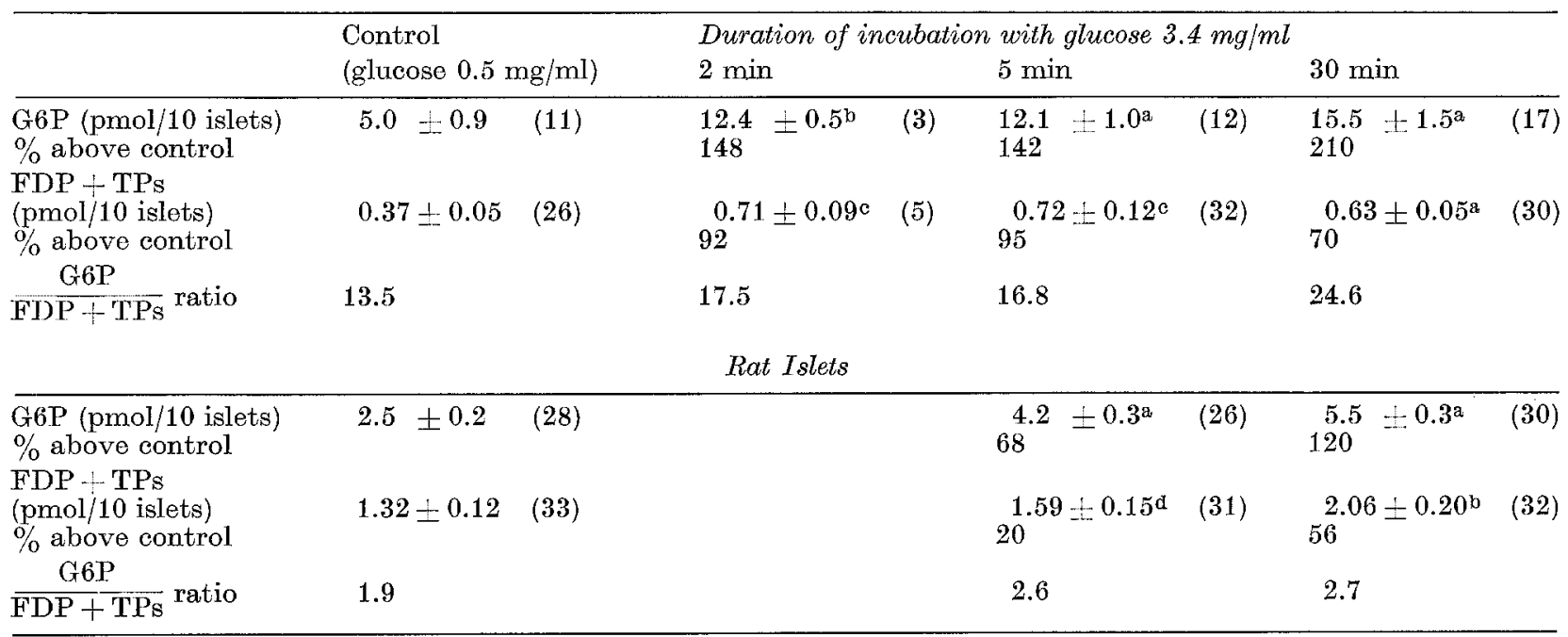

a Different from control with $p<0.001$

b Different from control with $p<0.005$

c Different from control with $p<0.02$

d NS, $p>0.2$

Batches of mouse or rat islets were preincubated for $30 \mathrm{~min}$ in $21 \mu \mathrm{l}$ bicarbonate medium containing albumin $(1 \mathrm{mg} / \mathrm{ml})$ and glucose $(0.5 \mathrm{mg} / \mathrm{ml})$. The medium glucose concentration was then raised to $3.4 \mathrm{mg} / \mathrm{ml}$ by injection of $7 \mu \mathrm{I}$ medium containing $12 \mathrm{mg} / \mathrm{ml}$ of glucose. After the times indicated islet metabolism was stopped by the injection of $\mathrm{HCl}$ and the islet contents of G6P and (FDP + TPs) were measured as described in the text. The data are expressed as mean \pm S.E.M. with the number of batches of islets under each condition given in parentheses.

ethanol and $1 \mathrm{mM} \mathrm{NaH}_{2} \mathrm{AsO}_{4}, 1.5 \mu \mathrm{l} 1 \mathrm{mM} \mathrm{NAD}{ }^{+}$and $1.5 \mu l$ of an enzyme mixture containing triosephosphateisomerase $(120 \mathrm{U} / \mathrm{ml})$, glyceraldehyde-3-phosphate dehydrogenase $(40 \mathrm{U} / \mathrm{ml})$ and aldolase $(4.5 \mathrm{U} / \mathrm{ml})$.

After incubation for $90 \mathrm{~min}$ at room temperature the content of NADH was measured in duplicate by the luciferase assay described below. The assay measures the sum of fructose-1,6-diphosphate and triose phosphates (FDP + TPs).

\section{Luciferase Assay}

Determination of NADH and NADPH was based on. the method described by P.E. Stanley [7].

Counting procedure: Polypropylene tubes $(1.3 \times 5.0$ $\mathrm{cm})$ were soaked overnight in water and washed with double distilled water. $1 \mathrm{ml}$ of a $0.1 \mathrm{M}$ trisbuffer $\mathrm{pH} 7.3$ containing $1 \mathrm{mM}$ mercaptoethanol was mixed with $2 \mu \mathrm{l}$ FMN $(0.1 \mathrm{mg}$ FMN $/ \mathrm{ml} 0.1 \mathrm{M}$ potassium phosphate buffer pH 7.0) and placed in a polypropylene tube. $10 \mu \mathrm{l}$ of a operated at room temperature was used. The photomultipliers were switched out-of-coincidence. Amplification was $100 \%$ and the discriminators were set between 10 and infinity.

\section{Results}

Since islet G6P and FDP were determined from standard curves prepared using authentic G6P and FDP taken through the same procedures, no corrections for recovery were needed. Typical standard curves for G6P and FDP in the luciferase assay are shown in the Figure.

The concentrations of G6P and (FDP $+\mathrm{TPs}$ ) in mouse and rat islets at various times after raising the 
extracellular glucose concentration from 0.5 to 3.4 $\mathrm{mg} / \mathrm{ml}$ are given in the Table. In mouse islets, the contents of G6P and (FDP + TPs) were both significantly raised after a two minute incubation at the high glucose concentration and remained elevated for at least $30 \mathrm{~min}$.

In rat islets, the G6P but not the (FDP + TPs) content was significantly increased after a $5 \mathrm{~min}$ exposure to high glucose (the shortest time interval tested). After a $30 \mathrm{~min}$ incubation both $\mathrm{G} 6 \mathrm{P}$ and (FDP + TPs) were significantly higher than at low glucose concentrations.

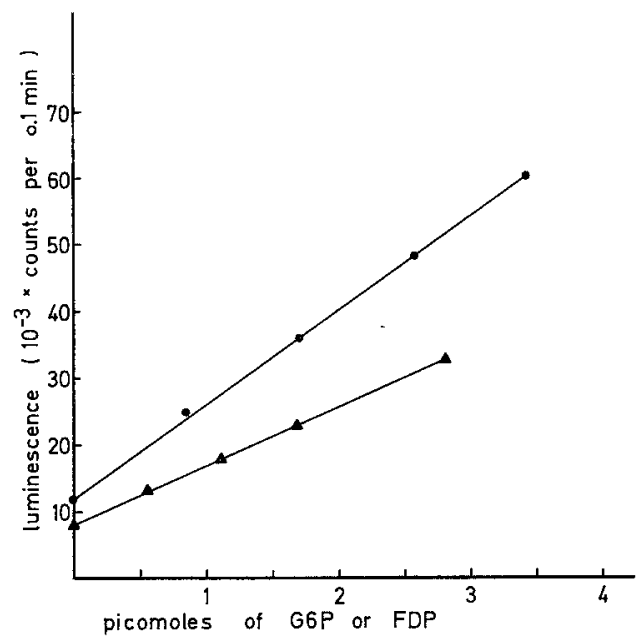

Fig. 1. Standard curves for $G 6 P$ and FDP using the luciferase assay. NADPH was generated from $G 6 P$ using $\mathrm{NADP}^{+}$and glucose-6-phosphate dehydrogenase. NADH was generated from FDP using $\mathrm{NAD}^{+}$, aldolase, triose phosphate isomerase and triose phosphate dehydrogenase. The reduced pyridine nucleotides formed were then determined by the luminescence produced by bacterial luciferase using a scintillation counter as detector. See the text for experimental details. Each point plotted is the mean of six determinations.

$\longrightarrow$ FDP, $\triangle-\triangle \mathrm{G} 6 \mathrm{P}$

Although mouse and rat islets are of similar size, there were differences between the absolute and relative contents of G6P and (FDP + TPs) in the two species. The G6P content was higher in mouse islets than in rat islets whereas the reverse was true for the (FDP + TPs) content. As a result the $[\mathrm{G} 6 \mathrm{P}] /[\mathrm{FDP}+\mathrm{TPs}]$ ratio was some tenfold higher in mouse islets than in rat islets. In mouse islets, increasing extracellular glucose concentration was associated with an increase (approx. $100 \%$ ) in the $[\mathrm{G} 6 \mathrm{P}] /[\mathrm{FDP}+\mathrm{TPs}]$ ratio; in rat islets this increase was much less marked.

\section{Discussion}

The view that glucose must be metabolized in order to elicit insulin release envisages that effects on insulin release of changes in the extracellular glucose concentration are mediated, at least in part, by changes in the intracellular concentration of one or more metabolites formed from glucose in the $\beta$-cell. It should be emphasized that neither the magnitude nor the direction of the changes in such a hypothetical trigger metabolite need parallel the changes in insulin secretion rate; however, the rapidity of the metabolite concentration change should be comparable to that of the secretory response.

In islets from several species, increasing extracellular glucose concentrations have been shown to give rise to increased islet content of hexose phosphates $[3,8,9]$. In an earlier study [8], we showed that a correlation existed between insulin release rate and hexose phosphate content of mouse islets under various conditions. Glucose-6-phosphate was shown to attain a steady state level in mouse islets after $15 \mathrm{~min}$ of incubation but the rapidity of changes in the $\mathrm{G} 6 \mathrm{P}$ level in response to changes in extracellular glucose concentration was not further investigated. Earlier studies of the kinetics of changes in islet content of glycolytic intermediates have yielded conflicting results; whereas very rapid $(<90$ sec) changes were observed in islets from obese-hyperglycemic mice on rapid elevation of blood glucose in vivo [3], no changes were found in rat islets after 5 min [4]; 60 min after elevation of blood glucose rat islets did show an increase in hexose phosphate content. When similar measurements were carried out on islets from a perfused rat pancreas preparation, no significant changes in islet metabolic intermediates were seen at any time up to $40 \mathrm{~min}$ after acute elevation of the extracellular glucose concentration [4]. It was argued that the rapid initial insulin secretory response to sugars could not be mediated by these intermediates. A recent report, however, has described fast $(1 \mathrm{~min})$ decreases in the islet content of glycolytic intermediates in islets from duct-ligated rat pancreas in response to high glucose [10].

Our data show that mouse and rat islets both evince significant and rapid changes in G6P content after elevation of extracellular glucose concentration. (FDP $+\mathrm{TPs}$ ) content is also increased after $30 \mathrm{~min}$; however, whereas the change in (FDP + TPs) content occurs in less than $2 \mathrm{~min}$ in mouse islets the rate of increase of (FDP + TPs) concentration in rat islets is sluggish, no significant increase being seen after $5 \mathrm{~min}$. These results confirm that there are indeed differences in the metabolic responses to an increased extracellular glucose concentration between mouse and rat islets but suggest that these differences are quantitative rather than qualitative. In particular they indicate that changes in hexose phosphate content of rat islets although less marked than for mouse islets occur within $5 \mathrm{~min}$ after raising the glucose concentration. These findings are thus consistent with the hypothesis that the insulin secretory response to glucose may be mediated by a metabolite of the sugar.

The relative amounts of $\mathrm{G} 6 \mathrm{P}$ and (FDP $+\mathrm{TPs}$ ) in isolated rat islets in the present study are similar to those reported for islets in a perfused rat pancreas preparation [4]. It is striking that in mouse islets the 
$[\mathrm{G} 6 \mathrm{P}] /[\mathrm{FDP}+\mathrm{TPs}]$ ratio is some ten-fold higher than in the rat islets. The enzymic basis for this difference is not known. In mouse islets the high $K_{m}$ for glucose utilization [11] is to some extent explicable in terms of the high $\mathrm{K}_{\mathrm{m}}$ glucose-phosphorylating activity and the glucose-inhibited glucose-6-phosphatase activity [3, 12]; in view of the failure to demonstrate these activities in rat islets $[4,13]$ and the low $\mathrm{K}_{\mathrm{m}}$ for glucose of hexokinase, the increased glucose oxidation rate in rat islets as the glucose concentration is raised from 3 to $20 \mathrm{mM}$ [14] is puzzling. It has been suggested that the phosphofructokinase reaction may be the step that is stimulated by the addition of glucose; the evidence for this was a decrease in the $[\mathrm{G} 6 \mathrm{P}] /[\mathrm{FDP}+\mathrm{TP}]$ ratio in rat islets when the extracellular glucose concentration was raised from zero to $20 \mathrm{mV}$ [4]. Under the conditions of our experiments, however, no such decrease was observed; indeed in mouse islets a marked increase was found. These data do not support the view that phosphofructokinase was activated other than by a rise in substrate concentration. They are consistent with the increased glycolytic rate in response to a raised extracellular glucose concentration arising primarily from an increase in the velocity of the ratedetermining step for glucose uptake, which in view of the rapid permeation of glueose into islets $[3,15]$, is likely to be phosphorylation of glucose.

Acknowledgements. This work was supported by grants from the Danish Medical Research Council (grant 5121512), the P. Carl Petersen Foundation and Nordisk Insulinfond. We thank Anne-Marie Fabricius and Anette Garval for expert and enthusiastic technical assistance.

\section{References}

1. Randle, P.J., Ashcroft, S.J.H., Gill, J.R.: In : Carbohydrate Metabolism and its Disorders, p. 427. Ed. Dickens, F., Randle, P.J., Whelan, W.J. London: Academic Press 1968.

2. Grodsky, G.M., Batts, A.A., Bennet, L.L., Vcella, C., Mc Williams, N. B., Smith, D. F. : Amer. J. Physiol. 205, $63(1963)$.

3. Matschinsky, F. M., Ellerman, J.E. : J.biol. Chem. 243, $2730(1968)$.

4. Matschinsky, F.M., Landgraf, R., Ellerman, J.E., Kotler-Brajtburg, J.: Diabetes 21 (Suppl. 2) 555 (1972).

5. Coll-Garcia, E., Gill, J.R.: Diabetologia 5, 61 (1969).

6. Krebs, H. A., Henseleit, K. Hoppe-Seylers Z. physiol. Chem. 210, 33 (1932).

7. Stanley, P.E.: Analyt. Biochem. 39, 441 (1971).

8. Asheroft, S.J.H., Hedeskov, C.J., Randle, P.J.: Biochem. J. 118, 143 (1970).

9. Montague, W., Taylor, K.W.: Biochem. J. 115, 257 (1969).

10. Mayhew, D.A., Corkey, B.E.: Diabetes 21 (Suppl. 1), $61(1972)$.

11. Asheroft, S.J.H., Weerasinghe, L.C.C., Randle, P.J.: Biochem. J. 126, 525 (1972).

12. Ashcroft, S.J.H., Randle, P.J.: Biochem. J. 119, 5 (1970).

13. Täljedal, I.-B.: Biochem. J. 114, 387 (1969).

14. Jarrett, R.J., Keen, H.: Laneet 1966 I, 633.

15. Hellman, B., Sehlin, J., Täljedal, I.-B.: Biochem. biophys. Acta 241, 147 (1971).

Dr. C.J. Hedeskov

Universitetets biokemiske Institut A

Tuliane Mariesvej 30

DK-2100 Copenhagen

Denmark 